\author{
MEMBUAT KALKULATOR DENGAN BORLAND DELPHI \\ TRI HAMSAH \\ 165100084 \\ Fakultas Komputer, 448757308 \\ trihamsah.student@umitra.ac.id
}

\begin{abstract}
Saat ini, informatika memiliki perkembangan yang sangat pesat. Informatika sendiri yaitu disiplin ilmu teknik yang mengenai masalah tranformasi atau pengolahan fakta simbolik dengan menggunakan computer melalui proses proses logika dalam informatika, hal yang paling berbungan adalah bahasa pemograman atau bahasa komputer.
\end{abstract}

Kata Kunci : membuat kalkulator dengan Borland delphi

\begin{abstract}
A. INTRODUCTION
Materi

Logika Program

Pertama-tama langkah yang harus dilakukan untuk membuat program Kalkulator di Delphi 7 yaitu mendesain form dengan menggunakan tombol edit, button, dan panel, lalu ubah captionnya
\end{abstract}

Lalu pada Edit1 ubah ReadOnly menjadi True agar Edit1 tidak berupa inputan dari keyboard.

Kemudian double click pada button 1 , lalu ketik kodingan berikut ini :

begin

Edit1.Text:=Edit1.Text+'1';

end;

Maksud dari kodingan diatas yaitu setiap mengklik button1, program akan menyimpan angka 1 tersebut berupa text dan akan ditampilkan pada Edit1 yang berfungsi sebagai layar kalkulator.

Begitu juga selanjutnya double click pada button 2 s.d. 0 dan . (titik) ketik kodingan seperti diatas, hanya diubah dalam kutipnya saja misalkan Edit1.Text:=Edit1.Text+'2'; u ntuk button 2 , dan seterusnya untuk button berikutnya.

Kemudian double click pada button $\mathrm{C}$, lalu ketik kodingan berikut ini :

begin

Edit1.Text:=";

end;

Maksud dari kodingan diatas bahwa jika kita mengklik button $\mathrm{C}$, program akan menghapus hasil inputan kita 
pada Edit1, jadi layar kalkulatornya akan kosong.

Kemudian tambahkan kodingan berikut ini dibagian var :

var

Form1: TForm1;

a,b,c : real;

tambah,kurang,kali,bagi : integer;

Maksud kodingan diatas adalah untuk mendeklarasikan variabel a,b,c dengan tipe data real dan variabel tambah,kurang,kali,bagi dengan tipe data integer yang nantinya akan digunakan pada kodingan berikutnya.

Kemudian double click pada button + , lalu ketik kodingan berikut ini :

begin

a:=StrToFloat(Edit1.Text);

tambah:=1;

Edit1.Text:=";

end;

Maksud kodingan diatas yaituStrToFloat(Edit1.Text); berfungsi untuk mengubah tipe data string dari data Edit1 menjadi tipe data float (real), yang nantinya akan disimpan dalam variabel a.

Begitu juga selanjutnya double click pada button -,*,dan/ ketik kodingan seperti diatas, hanya diubah dibagian tambah:=1; menjadikurang:= 1; pada button - , dan seterusnya untuk button berikutnya.

Kemudian double click pada button $=$, lalu ketik kodingan berikut ini :

begin

$\mathrm{b}:=$ StrToFloat(Edit1.Text);

if (tambah > 0) then

begin

$c:=a+b$;

Edit1.Text:=FloatToStr(c);

$\mathrm{a}:=0$;

$\mathrm{b}:=0$;

tambah:=0;

end;
Maksud kodingan diatas yaituStrToFloat(Edit1.Text); berfungsi untuk mengubah tipe data string dari data Edit1 menjadi tipe data float (real), yang nantinya akan disimpan dalam variabel b. Kemudian pada program ini menggunakan perulangan if dimana akan berjalan jika variabel tambah pada kodingan sebelumnya > 0 . Lalu jika tambah $>0$, program memproses ke tahapc: $=a+b ;$ maksudnya adalah variabel c akan menyimpan hasil penjumlahan antara variabel a dengan b, dan akan diubah dari tipe data float (real) menjadi string kembali yang nantinya akan ditampikan di Edit1 atau pada layar kalkulator tersebut.

if (kurang > 0) then

begin

$\mathrm{c}:=\mathrm{a}-\mathrm{b}$

Edit1.Text:=FloatToStr(c);

$\mathrm{a}:=0$

$\mathrm{b}:=0$;

kurang: $=0$;

end;

Maksud kodingan diatas yaituStrToFloat(Edit1.Text); berfungsi untuk mengubah tipe data string dari data Edit1 menjadi tipe data float (real), yang nantinya akan disimpan dalam variabel b. Kemudian pada program ini menggunakan perulangan if dimana akan berjalan jika variabel kurang pada kodingan sebelumnya $>0$. Lalu jika kurang $>0$, program memproses ke tahap c: $=a-$ b;maksudnya adalah variabel c akan menyimpan hasil pengurangan antara variabel a dengan $b$, dan akan diubah dari tipe data float (real) menjadi string kembali yang nantinya akan ditampikan di Edit1 atau pada layar kalkulator tersebut.

if (kali > 0) then 


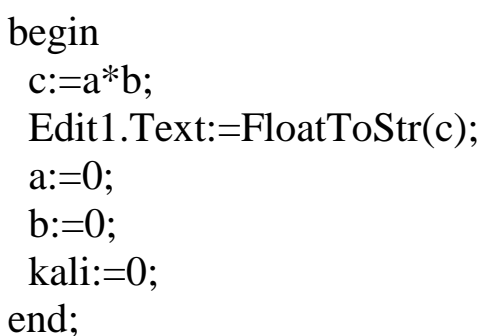

Maksud kodingan diatas yaituStrToFloat(Edit1.Text); berfungsi untuk mengubah tipe data string dari data Edit1 menjadi tipe data float (real), yang nantinya akan disimpan dalam variabel b. Kemudian pada program ini menggunakan perulangan if dimana akan berjalan jika variabel kali pada kodingan sebelumnya $>0$. Lalu jika kali > 0, program memproses ke tahapc:=a*b;maksudnya adalah variabel $c$ akan menyimpan hasil perkalian antara variabel a dengan $b$, dan akan diubah dari tipe data float (real) menjadi string kembali yang nantinya akan ditampikan di Edit1 atau pada layar kalkulator tersebut.

if (bagi > 0) then

begin

$\mathrm{c}:=\mathrm{a} / \mathrm{b}$

Edit1.Text:=FloatToStr(c);

$\mathrm{a}:=0$

$\mathrm{b}:=0$;

bagi: $=0$;

end;

end;

end.

Maksud kodingan diatas yaituStrToFloat(Edit1.Text); berfungsi untuk mengubah tipe data string dari data Edit1 menjadi tipe data float (real), yang nantinya akan disimpan dalam variabel b. Kemudian pada program ini menggunakan perulangan if dimana akan berjalan jika variabel bagi pada kodingan sebelumnya $>0$. Lalu jika bagi $>0$, program memproses ke tahapc:=a/b;maksudnya adalah variabel c akan menyimpan hasil pembagian antara variabel a dengan $b$, dan akan diubah dari tipe data float (real) menjadi string kembali yang nantinya akan ditampikan di Edit1 atau pada layar kalkulator tersebut.

\section{B. CONCLUSION}

Kesimpulan dari materi ini adalah bahasa pemograman adalah kumpulan perintah perintah yang bermaknadan berstruktur yang dimengerti oleh computer yang berguna dalam penyelesaian masalah. Bahasa pemograman sudah dipakai sejak computer ada dan berkembang sampai sekarang. Bahasa pemograman bibagi menjadi 4 kelompok, yaitu object oriented language ( visual data base, visual foxpro, Delphi, visual C), high level (seperti pascal dan basic), middle level(seperti bahas C) dan low level (seperti bahasa assembly) terdapat macam macam bahasa pemograman, antara lain adalah Delphi, bahasa $\mathrm{C}$, visual basic, dan lain lain.

\section{ACKNOWLEDGEMENT University Of Indonesia University Of Mitra Indonesia Telkom University University Of Mellbourne Saitama University}




\section{REFERENCE (Based ISO 690 )}

[2] A. S. Putra, O. M. Febriani, And B. Bachry, "Implementasi Genetic Fuzzy System Untuk Mengidentifikasi Hasil Curian Kendaraan Bermotor Di Polda Lampung," J. Sist. Inf. Dan Manaj. Basis Data, Vol. 1, No. 1, Pp. 21-30, 2018.

[3] O. M. Febriani And A. S. Putra, "Sistem Informasi Monitoring Inventori Barang Pada Balai Riset Standardisasi Industri Bandar Lampung," J. Inform., Vol. 13, No. 1, Pp. 90-98, 2014.

[4] Putra, Arie Setya. "2018 Artikel Struktur Data, Audit Dan Jaringan Komputer." (2018).

[5] Putra, A. S. (2018, July 17). Paperplain Fundamental Create Application With Borland Delphi 7.0 University Of Mitra Indonesia. Retrieved From Osf.Io/Pbrn9.

\section{E. REFERENCE (Based APA)}

Putra, A. S., Aryanti, D. R., \& Hartati, I. (2018, November). Metode SAW (Simple Additive Weighting) sebagai Sistem Pendukung Keputusan Guru Berprestasi (Studi Kasus: SMK Global Surya). In Prosiding Seminar Nasional Darmajaya (Vol. 1, No. 1, pp. 85-97).

Sari, D. P., Febriani, O. M., \& Putra, A. S. (2018, November). Perancangan Sistem Informasi SDM Berprestasi pada SD Global Surya. In Prosiding Seminar Nasional Darmajaya (Vol. 1, No. 1, pp. 289-294).

Putra, A. S. (2018). Paperplain: Execution Fundamental Create Application With Borland Delphi 7.0 University Of Mitra Indonesia.

Putra, A. S., Sukri, H., \& Zuhri, K. Sistem Monitoring Realtime Jaringan Irigasi Desa (JIDES) Dengan Konsep Jaringan Sensor Nirkabel. IJEIS (Indonesian Journal of Electronics and Instrumentation Systems), 8(2), 221232.

Darmawan, A., Yuliawati, D., Marcella, O., \& Firmandala, R. (2016). Sistem Absensi dan Pelaporan Berbasis Fingerprint dan SMS Gateway. EXPLORE, 7(1).

Febriani, O. M., Wahyuni, T., \& Yusuf, S. (2017). DESIGN OF 


\section{WEBSITE-BASED INFORMATION SYSTEM FOR EDOCUMENT ADMINISTRASI IN THE COMMUNITY SERVICE UNIT (A Case Study at Rajabasa District). INTERNATIONAL JOURNAL OF COMPUTERS \& TECHNOLOGY, 16(7), 7010-7020.}

Febriani, O. M., \& Wahyuni, T. (2017, October). PERANCANGAN SISTEM E-DOCUMENT ADMINISTRASI LOGBOOK PENELITIAN PADA UNIT LAYANAN DI BANDAR LAMPUNG. In Prosiding Seminar Nasional Darmajaya (Vol. 1, No. 1, pp. 187-194).

Febriani, O. M., \& Permadi, A. B. (2017). Implementasi Sistem Aplikasi Data Bimbingan dan Pelanggaran Siswa pada Sekolah Menengah Atas di Lampung Tengah dengan Metode Analisis dan Desain Sistem Terdistribusi (SSAD). EXPERT, 7(1).

Febriani, O. M., \& Ambarwati, L. (2015). PERANCANGAN APLIKASI PENGOLAHAN DATA PENJUALAN UKM KELANTING KHAS TELO DESA SIDOHARJO KECAMATAN JATI AGUNG KABUPATEN LAMPUNG SELATAN. Jurnal Teknologi Informasi dan Bisnis Pengabdian Masyarakat Darmajaya, 1(1), 77-95.

Febriani, O. M. (2015). Rancang Bangun Aplikasi Ecommercemenggunakan Freewebstore pada UKM Kelanting di Desa Sidoharjo Lampung Selatan. Prosiding Sembistek 2014, 1(02), 446-458. 